\title{
J
}

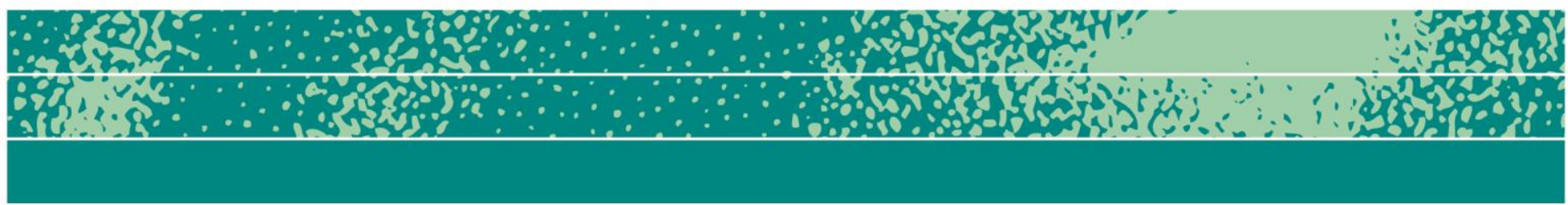

\section{A Commentary on "The Senses in Anthropological and Marketing Research: Investigating a Consumer-Brand Ritual Holistically"}

\author{
Aradhna Krishna
}

Malefyt (2014) has opened up a large field of study by highlighting the importance of examining sensory perception in the ritualistic use of products and brands. This area of study has thus far not been explored by psychologists-cognitive and consumer-or by anthropologists. In order to understand why this is an important contribution, I will focus first on what these different fields do.

Cognitive and consumer psychologists both focus on mental processes such as thinking, perceiving, remembering, and learning. However, consumer psychologists further focus on the aspects of thinking, perceiving, remembering, and learning as they pertain to the consumer context-situations such as purchasing and consuming. The consumer psychologist may also use marketing stimuli (such as brands and advertisements) to study the basic concepts of thinking, perceiving, remembering, and learning. Whereas cognitive psychologists typically make their home in psychology departments, consumer psychologists are housed in marketing departments of business schools. The differences highlighted here between cognitive and consumer psychologists also apply in a somewhat similar manner to social/cultural anthropologists versus consumer anthropologists.
Page 1 of 5

JBA 4(1): 31-35 Spring 2015

(C) The Author(s) 2015 ISSN 2245-4217

www.cbs.dk/jba 
Both cognitive psychologists (e.g., Harlow 1958), and more recently consumer psychologists (e.g., Cian, Krishna, Elder 2014), have studied the field of sensory perception. In consumer psychology, research on the five separate senses which focuses on consumer behavior has been brought together under the umbrella of sensory marketing, defined as, "marketing that engages the consumers' senses and affects their perception, judgment, and behavior" (Krishna, 2012, p. 332; for reviews, see Krishna, 2012, 2013, and the contributions in Krishna, 2010). In cognitive psychology, the dominant belief of cognition and perception being independent was challenged by the belief that mental activity is grounded in sensory experience (for reviews, see Barsalou, 2008; Meier, Schnall, Schwarz, \& Bargh, 2012; Niedenthal, Barsalou, Winkielman, KrauthGruber, \& Ric, 2005). Empirical support for the latter quickly built up, so that it was soon difficult for the amodal model of the human mind to be credible.

Aside from establishing a modal (sensorially-grounded) basis for cognition, both cognitive and consumer psychologists have spent considerable effort on showing how context impacts sensory perception. Thus, akin to anthropology, a basic premise of psychology has also been that sensory perception is malleable and dependent on context. One example of this is evidenced in the stream of studies on sensoryinteraction, whereby change in the input from one sense affects perception of another. Thus, Krishna and Morrin (2008) show how the haptic quality of a disposable plastic cup (whether it is flimsy or firm) can affect the perceived taste of the water. In their studies, the subjects do not drink the water directly from the cup (which could affect mouth feel), but through a straw which is kept constant across the firm and flimsy cups. Similarly, Krishna, Elder, and Caldara (2010) show that smells (which are perceived to be cold versus hot, and operationalized through a sea-island-cotton versus a pumpkin-cinnamon smell) can impact the perceived effectiveness of therapeutic gel-packs: the heating packs are considered more effective at heating the human body when infused with a hot (versus cold) smell whereas the cooling packs are considered more effective at cooling when infused with a cold (versus hot) smell.

As such, I would modify two statements made by Malefyt in the article which this commentary accompanies. First, I would modify the statement that "Anthropology, in particular, turns our attention away from previous considerations of the senses as biologically determined and universally fixed, to more interactive, adaptable and fluid concepts of the senses that are continuously shaped by culture, geography and history." I believe that for at least two decades now, psychology has treated sensory perception as not being fixed, but being malleable; and that anthropology is adopting the same approach as psychology for studying sensory perception. Second, I would modify the statement, "As opposed to dividing the body and mind, and treating the senses as biological vehicles that merely channel information to the brain, 
anthropologists and sociologists regard the active interplay among sensory experience, emotion, memory and cognition as deeply contingent upon situated meaning and context". In fact, I would propose that psychologists have been at the forefront of the debate about whether cognition is modal or amodal. Anthropologists agree that cognition is modal and also agree that sensory perception is context-dependent.

In my view, the difference between an anthropologist's and a psychologist's focus on sensory perception is not in their understanding of the "concept of sensory perception", but in what aspects of sensory perception they choose to study, and the methods they use to study these aspects. Clearly, certain methods are more apt to study certain questions, and the two are related. As Malefyt points out, "Ethnographic analysis of a ... ritual highlights the qualitative aspects of consumer sensory engagement, which are less available through marketing approaches of experimental design or statistical studies of the senses." Thus, (as an example) anthropologists use ethnographic studies which allow them to study rituals; psychologists use experiments to study (for instance) memory for certain information, or reaction to certain information.

I also find another difference between anthropological and psychological studies which is not highlighted by earlier researchers. I believe that, while psychologists focus on commonalities in human perception and behavior, anthropologists thrive on differences in human perception and behavior-if all examples in the ethnographic study were the same, would the study be interesting? In this vein, Malefyt shows that sensory perception literature can be enriched by ethnographic studies looking at how individuals make their product consumption more or less sensorially engaging. The examples he offers regarding sensory dimensions of the shaving ritual are varied and extremely insightful-these include stirring the brush and foaming up lather, the warmth of the lather, the smell of a morning routine, the audible feedback of the blade gliding on the skin-which, besides telling the shaver that the job is being done right, also give a sense of accomplishment.

Malefyt also brings forth another subtle aspect of what the ethnographic approach allows anthropologists to study, "sensory experience (as being) generated between and among people, places and events, rather than in an individual's body" (Hsu 2008). I feel that while much work on sensory perception has been done on exploring intrahuman interactions (how one sense affects perception of another?), little research explores human-place (how does place affect sensory perception?), human-event (how do past or future anticipated events affect sensory perception?), and human-human (how does the presence of one human affect sensory perception of another?) interactions.

How can anthropologist and psychologist inform each other? Neuroscience and psychology have had a symbiotic relationship for decades-psychology demonstrates behavior which makes 
neuroscientists wonder about linkages in the brain; and neuroscience demonstrates linkages in the brain which make psychologists ponder if certain behaviors will be exhibited. A similar synergistic relationship can be encouraged between anthropologists and psychologists. In looking for commonalities, the psychologist misses nuances of consumer behavior that the anthropologist brings to light and which can be further studied by psychologists. Thus, I can see, for instance, consumer psychologists studying further audible feedbacks of products in the consumption process. Anthropologists, in turn, could benefit from psychology studies in identifying issues of interest. Clearly, there are topics of mutual interest. As noted earlier, both fields have been inspired by the mindbody connection, by context affecting sensory perception, and both fields have now studied sensory marketing.

\section{References}

Barsalou, L. W. (2008). “Grounded cognition.” Annual Review of Psychology, 59(1), 617-645.

Cian, L., A. Krishna and R. Elder (2014), "This Logo Moves Me: Dynamic Imagery from Static Images.” Journal of Marketing Research, 51 (2), 184197.

Harlow, H. F. (1958). "The nature of love." American Psychologist, 13(12), 673-685.

Krishna, A. (2010). Sensory marketing: Research on the sensuality of products. New York: Routledge.

Krishna, A. (2012). "An Integrative Review of Sensory Marketing: Engaging the Senses to Affect Perception, Judgment and Behavior." Journal of Consumer Psychology, 22(3), 332-351.

Krishna, A. (2013). Customer Sense: How the 5 Senses Influence Buying Behavior. New York: Palgrave Macmillan.

Krishna, A., R. Elder, and C. Caldara (2010), "Feminine to Smell but Masculine to Touch? Multisensory Congruence and its Effect on the Aesthetic Experience." Journal of Consumer Psychology, 20 (4), 410-418.

Krishna, A., \& Morrin, M. (2008). "Does touch affect taste? The perceptual transfer of product container haptic cues." Journal of Consumer Research, 34, 807-818.

Malefyt, T. de W. (2015). "The Senses in Anthropological and Marketing Research: Investigating a Consumer-Brand Ritual Holistically." Journal of Business Anthropology, 4(1).

Meier, B. P., Schnall, S., Schwarz, N., \& Bargh, J. (2012). “Embodiment in social psychology.” Topics in Cognitive Science, 4, 705-716. 
Niedenthal, P. M., Barsalou, L. W., Winkielman, P., Krauth-Gruber, S., \& Ric, F. (2005). „Embodiment in attitudes, social perception, and emotion.”

Personality and Social Psychology Review, 9, 184-211.

Aradhna Krishna is the Dwight F. Benton Professor of Marketing at the Ross School of Business, University of Michigan. She is considered the pioneer of the field of sensory marketing. In more than fifty published articles, she has explored ways in which a product's look, feel, taste, sound, and smell contribute to how it is perceived, and how people respond to these perceptions. Prof. Krishna organized the first academic conference on sensory marketing (in 2008), bringing together psychologists, neuroscientists, marketing academics and practitioners. She edited and contributed to the book, Sensory Marketing: Research on the Sensuality of Products, in 2009. In 2013, she published another book, Customer Sense: How the 5 Senses Influence Buying Behavior, which Kirkus Reviews calls "A sophisticated, easy-handed elucidation of the practice of marketing to our senses." Prof. Krishna is considered one of the 50 most productive marketing professors in the world. Harvard Business Review recently acknowledged her as "the foremost expert in the field" of sensory marketing. In recognition of her outstanding contributions to consumer psychology, she was awarded as a Fellow of the Society for Consumer Psychology, the organization's highest honor. She may be reached at aradhna@umich.edu 